\title{
VERTICAL DISTRIBUTION AND ABUNDANCE OF COPEPOD NAUPLII AND ICHTHYOPLANKTON IN NORTHERN BAJA CALIFORNIA DURING STRONG INTERNAL TIDAL FORCING.
}

Laura Ibáñez-Tejero ${ }^{a}$, Lydia B. Ladah ${ }^{\text {** }}$, Laura Sánchez-Velasco ${ }^{\text {a }}$ Eric D. Barton ${ }^{\mathrm{c}}$, Sylvia Patricia Adelheid Jiménez-Rosenberga

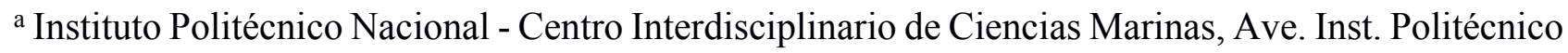
Nacional s/n, CP 23096, La Paz, BCS, Mexico.

b Dept. of Biological Oceanography, CICESE, Centro de Investigación Científica y Educación Superior de Ensenada, Carretera Ensenada-Tijuana 3918, Zona Playitas, CP 22860 Ensenada, BC, Mexico.

${ }^{\mathrm{c}}$ Instituto de Investigaciones Marinas - CSIC, Eduardo Cabello 6, Vigo, CP 36208, Spain.

*corresponding author at 1 ladah@,cicese.mx

\begin{abstract}
In this study, we explored the changes in the vertical distribution and abundance of copepod nauplii and ichthyoplankton every hour in three different strata during a period of strong internal tides, which have been shown to accumulate and transport plankters. In the deeper stratum, the abundance of copepod nauplii was significantly greater, significantly increased during the cold phase of the internal tide, and was significantly correlated with both total and baroclinic current flows in the direction of internal tide propagation. On the other hand, ichthyoplankton abundance was generally low, with no stratification in vertical distribution, no significant changes across the two phases of the internal tide, and no correlation at any depth with any current flows. The cold phases of the internal tide were characterized by a shallow thermocline, a cooler water column, and a significant increase in the abundance of copepod nauplii in the bottom stratum. On the other hand, the warm phases of the internal tide were characterized by abrupt warming in surface waters, a depression of the thermocline, and a significant decrease of copepod nauplii in the bottom stratum. The depth distribution and buoyancy of the different groups of larvae may be responsible for the differences found.
\end{abstract}

KEY WORDS: early stages, copepod nauplii, ichthyoplankton, internal tide, buoyancy control 


\section{INTRODUCTION}

The relationship between zooplankton and physical processes has been relatively well-studied at different spatiotemporal scales (Haury et al., 1978), particularly for seasonal and mesoscale processes. Aggregations of planktonic organisms have been associated with mesoscale phenomena such as fronts (McCulloch and Shanks, 2003; Shanks and McCulloch, 2003) and upwelling (Morgan et al., 2009; Morgan and Fisher, 2010), which can modify both the distribution and abundance of plankters. However, the effect of higher-frequency coastal processes, such as internal tidal waves, on the distribution and abundance of zooplankton has not been studied with the same detail, especially for early stages, and the literature to date has mainly focused on cyprid barnacle larvae (e.g. Pineda 1991,1999; Tapia and Pineda, 2007; Tapia et al., 2010). Understanding how internal tidal waves modulate the distribution and abundance of other zooplankton groups has been largely neglected, in part due to the high frequency sampling effort required to detect changes in the distribution and abundance of organisms at shorter temporal and spatial scales.

Internal tides are known to cause significant changes in water column properties at short temporal scales (Ladah et al., 2012). In a stratified water column, abrupt bathymetry promotes the generation of internal tides, often forced by the barotropic tide (e.g. Baines, 1982; Vlasenko et al., 2005; Lamb, 2013). The internal tide manifests as an internal wave associated with current shear at the tidal frequency near the coast (Helfrich and Melville, 2006; Lamb, 2013). Propagation dynamics are characterized by two alternating phases and associated baroclinic flows (Pineda, 1994). The cold phase is characterized by the flow of cold water shoreward at depth, with offshore currents near the surface. When the cold bottom water nears the shore, it upwells, generating a hydrostatic instability that promotes vertical mixing near the coast (Sandstrom and Elliot, 1984; Pineda, 1994). During the warm phase, the colder water previously upwelled nearshore sinks and flows offshore at depth, while warmer waters are advected onshore at the surface (Pineda, 1994). This complex and dynamic system produces strong thermal fronts, identified by abrupt and rapid changes in temperature (Pineda, 1991). These are often accompanied by non-linear internal waves of higher-frequency (e.g. Helfrich and Melville, 2006) that can be observed as surface slicks.

Internal waves have been proposed as a mechanism for transport of particles and plankton (e.g. Shanks, 1983; Pineda, 1991; Lamb, 1997, 2002; Helfrich and Pineda, 2003), either through small displacements by high frequency solitary waves, which may cause substantial transport when they occur in packets (Lamb, 1997), through transport by trapped cores in solitons (Lamb, 2002), through advection if they are concentrated in front of, behind or offshore of the propagating feature (Franks 1997, Helfrich and Pineda 2003), especially for inefficient swimmers, or through accumulation by 
avoiding downwelling at the front by more buoyant particles and better swimmers (Helfrich and Pineda 2003). Transport and accumulation, regardless of the mechanism, depends on the vertical and spatial distribution, specific behaviour, and buoyancy of the marine larvae in question and their ability to respond to flows by either swimming, sinking or floating (Helfrich and Pineda, 2003).

Most studies have focused on the effect of internal tides on benthic meroplankton (e.g. Pineda 1994, 1999; Ladah et al., 2005; Tapia and Pineda, 2007), whose early life stages require transport to the coast to complete their life history and settle in the littoral zone (Pineda et al., 2007). Early stages of barnacles can be accumulated above the thermocline (Liévana-MacTavish et al., 2016) and can then be transported to the coast in surface water during the warm phase of the internal tide (Pineda et al., 2007). Conversely, larval crabs have been observed in cold water below the thermocline (Leichter et al., 1998), and increase their abundance during the cold phase of the internal tide at depth (LiévanaMacTavish et al., 2016), potentially due to advection from offshore deeper waters. Both the depth distribution of these organisms (Tapia et al., 2010; Liévana-MacTavish et al., 2016, LiévanaMacTavish and Ladah, 2017), and their behaviour (Pineda, 2000; Pineda et al., 2009; Pineda and Reyns, 2018) can determine where, when and how their distribution and abundance changes during the internal tide. However, it is practically unknown how the internal tide affects other meroplanktonic groups such as ichthyoplankton, and holoplanktonic organisms (e.g. copepods), which form important links in the marine trophic chain (Stibor et al., 2004).

The life stages of ichthyoplankton and holoplankton (e.g. copepods) have different displacement capabilities in the water column, depending on their ontogeny (Moser, 1996; Mauchline, 1998). In general, more mature life stages can control their buoyancy and swimming, while early life stages depend more on environmental conditions (Franks, 1992). For example, early copepod nauplii contain lipid droplets, which affect their buoyancy (Mauchline, 1998; Lee et al., 2006). They can move in all directions using their appendages, although they are weak swimmers (Mauchline, 1998). For early stages of ichthyoplankton, fish eggs begin with a yolk mass and an oil globule (Moser, 1996). When fish eggs hatch, fish larvae develop a yolk sac (Moser, 1996). Both fish eggs and vitelline larvae have positive buoyancy but with null swimming capacity (Pittman and McAlpine, 2001).

The corresponding depth distribution of ichthyoplankton and holoplankton, and their ability to swim, sink or float can affect their transport during internal tides (Franks, 1992). Higher abundances of adult and juvenile calanoid copepods have been reported to occur below the thermocline during internal tides (Haury et al., 1983; Leichter et al., 1998). On the other hand, fish larvae have been observed in surface slicks during internal tide events (Shanks, 1983; Kingsford and Choat, 1986). 


\section{METHODS}

The Bahia Todos Santos study site is a semi-enclosed bay located in the northern part of the Baja California peninsula in Mexico (Fig. 1). Its abrupt topography favours the generation and propagation of strong internal tides in summer when the water column is well stratified (Ladah et al., 2012; Filonov et al., 2014).

Physical and biological data were taken during the FLOO-2009 expedition at the N4 site (Fig. 1) on the 19-20 of August, 2009, during daylight hours (Liévana-MacTavish et al., 2016; Ibáñez-Tejero et al., 2018). Zooplankton sampling was carried out with a conical plankton net (150 $\mu \mathrm{m}$ mesh size with a mouth diameter of $0.5 \mathrm{~m}$ ), with a closing mechanism designed to sample different water column strata, with a flowmeter at the mouth to determine the amount of water sampled. Zooplankton was sampled from three different strata (surface, 0-6 m; mid-water, 6-15 m; and bottom 15-28 m), with a sample taken every $20 \mathrm{~min}$, resulting in an hourly cycle to cover the 3 strata. A thermistor chain (Onset HOBO TidbiT with \pm 0.2 degrees $\mathrm{C}$ accuracy) was deployed at $30 \mathrm{~m}$ depth, with loggers placed every meter between 3 and $26 \mathrm{~m}$ depth, which recorded temperature every minute. An Acoustic Doppler Current Profiler (Sentinel Workhorse ADCP, 614 kHz, Teledyne RD Instruments) was deployed at $30 \mathrm{~m}$ depth and recorded currents and echo intensity every $30 \mathrm{~s}$ in $1 \mathrm{~m}$ bins.

The warm phase of the internal tide was identified by abrupt changes in temperature that exceeded $2^{\circ} \mathrm{C}$ at $5 \mathrm{~m}$ depth. The cold phase was identified by temperatures $\leq 15^{\circ} \mathrm{C}$ at $9 \mathrm{~m}$ depth (see LiévanaMacTavish et al. (2016) for details).

The principal axis of variation of the current was calculated from the east and north components at each depth (Kundu and Allen, 1976) and the time series were rotated into the depth-averaged axis ( $\left.u^{\prime}, v^{\prime}\right)$. A second-order polynomial equation was then used to separate the tidal and subtidal processes in the bay (Ibáñez-Tejero et al., 2018). The subtidal flow was removed and internal tidal 
currents (U', V') were filtered through a Godin filter to remove the variability at periods $<60$ min (Godin, 1991).

Zooplankton was separated, identified and quantified. Aliquots of $25 \mathrm{~mL}$ (1/6 of the sample) were used to quantify copepod nauplii. To explore if an aliquot of $25 \mathrm{~mL}$ provided an adequate representation of the sample, for a subset of samples, copepod nauplii were quantified in the whole sample and compared to results from 3 different aliquots of $25 \mathrm{~mL}$. The estimated error of using aliquots to represent the entire sample was $<5 \%$. The entire sample was used to quantify fish eggs and larvae, independent of species. Subsequently, organism abundance was standardized using the volume of water filtered through the net and expressed in ind. $m^{-3}$. Fish larvae were identified to the highest taxonomic level possible (Moser, 1996).

\section{Statistical analysis}

A factorial ANOVA and a post hoc Fisher LSD test was used to analyse organism counts at an alpha of 0.05 (Zar, 2010) to explore the abundance of copepod nauplii and ichthyoplankton (fish eggs and larvae) in each internal tide phase (cold vs. warm) and in the surface and bottom collection strata, in order to examine if organism abundances increased in a particular phase of the internal tide and at what depth. We also explored if there was a significant relationship between organism abundance and the baroclinic (U', V') and total currents (u', v') in the stratum they were sampled from, averaged over a period of $30 \mathrm{~min}$ before and $30 \mathrm{~min}$ after (60 $\mathrm{min}$ in total) each biological sample collection time using a Pearson correlation (Zar, 2010), as in previous studies (Pineda, 1994; LiévanaMacTavish et al., 2016).

Pearson correlations (Zar, 2010) were also used to explore the relationship between environmental variables (temperature, sea level and total kinetic energy) and the abundance of copepod nauplii and ichthyoplankton (fish eggs and larvae) in the different strata (surface, mid-water and bottom). All environmental variables were again averaged for each stratum over the collection period as explained above for currents.

\section{RESULTS}

\section{Environmental conditions}

Sea level showed a tidal range of $\pm 1 \mathrm{~m}$ at a semidiurnal frequency (Fig. 2a). The time series of temperature and currents showed a semidiurnal internal tide during both days of study (Fig. 2b, c, d). 
Temperature data showed a stratified water column with the $15{ }^{\circ} \mathrm{C}$ isotherm associated with the position of the thermocline. Semidiurnal internal tidal waves were evident, particularly at the thermocline (Fig. 2b). Two cold phases and two warm phases of the internal tide occurred each day at a semidiurnal frequency. The cold phases were characterized by the pumping of cold $\left(\leq 15^{\circ} \mathrm{C}\right)$ water upwards. The warm phases were characterized by as strong increases in temperature $\left(>2^{\circ} \mathrm{C}\right)$ in a few minutes near the surface accompanied by a sinking of warm water in the mid-water stratum. High-frequency internal waves formed above the $15^{\circ} \mathrm{C}$ isotherm.

The baroclinic tide showed current speeds near $0.15 \mathrm{~m} \mathrm{~s}^{-1}$. The onshore current direction (U') was towards $34^{\circ}$ clockwise with respect to east (Fig. 2c). The alongshore current direction (V'), and the principal direction of propagation of the internal tidal was towards $56^{\circ}$ anticlockwise with respect to north (into the bay) (Fig. 2d).

\section{Vertical distribution and changes in abundance during the internal tide}

Although we found more fish larvae (10.54 ind. $\left.\mathrm{m}^{-3}\right)$ in the surface stratum on the first day of sampling (August 19) (Fig. 2c) and more fish eggs in the surface stratum (9.14 ind. $m^{-3}$ ) on the second day of sampling (August 20) during the warm phase of the internal tide (Fig. 2b), overall, fish egg and fish larvae abundances did not show any significant stratification (Fig. 2b, c, Fig. 3a,b, Table I), or changes between the cold and warm phases of the internal tide (Fig. 3a,b; Table I). The majority of ichthyoplankton consisted of fish eggs, and most (80\%) of the fish larvae identified had a yolk sac, showing the presence of early life stages in the area (see Table II). There was no significant relationship of fish egg or larvae abundances with any environmental variable (temperature, sea level, onshore currents, total kinetic energy, alongshore total or baroclinic currents) (Fig. 4, Table III).

On the other hand, copepod nauplii showed higher abundances at depth compared to the surface stratum (Fig. 3c; Table I), with the highest abundance on the first day of sampling in the deeper strata (2402 ind. $m^{-3}$ for 19 August) (Fig. 2d). A significant increase in abundance of copepod nauplii was found during the cold phase of the internal tide in the deeper stratum $(\mathrm{p}=0.001)$, with a significant interaction between internal tidal phase and sampling strata $(p=0.013$, Fig. $3 c$, Table I). During the warm phase, the abundance of copepod nauplii was significantly lower at all depths. The Pearson correlations did not show any significant relationship of copepod nauplii abundance with temperature, sea level, onshore currents or total kinetic energy. However, a significant relationship between alongshore current flows and the abundance of copepod nauplii in the deep stratum was found, with increased abundances at depth associated with both the overall and baroclinic current flow into the bay, in the southeastward direction (Fig. 4, Table III). 


\section{DISCUSSION}

In this study, early life stages of copepod nauplii showed significantly greater abundances in the deeper stratum during the cold phase of the internal tide, as was predicted for zooplankton with a stratified distribution with more larvae below the thermocline. Fish eggs and larvae, on the other hand, had low overall abundances, showed no clear stratification pattern in their distribution, and no significant changes in vertical distribution or abundance during any phase of the internal tide at any depth. Changes in organism abundance during the internal tide involves the interaction between vertical and spatial distribution, larval buoyancy, swimming ability, behaviour, preference for food and light, and predator avoidance (Franks, 1992; Pineda et al., 2009; Pineda and Reyns, 2018), which may all account for the differences found herein for the different groups of organisms. There is little lab work to explore the detailed response of these organisms to different flows, as there exists in the literature for barnacles (Helfrich and Pineda, 2003; Scotti and Pineda, 2007), making the interpretation of the mechanism behind the increase in abundance speculative. This study, however, does support the idea that not all stages and groups of zooplankton respond in the same way as described in the established literature for some merozooplankton during internal tidal forcing (Pineda, 1999; Liévana-MacTavish et al., 2016). This study further demonstrates that changes in abundance during the internal tide is a complex process involving a suite of factors that must be taken into consideration when making predictions about how organisms are accumulated and/or transported during dynamic coastal phenomena such as internal tides.

The higher abundances of copepod nauplii found at depth may be related with the location of hatching copepod eggs, which are dense and sink in the column water, sometimes even as resting stages on the benthos (Mauchline, 1998). Copepod nauplii are often found in deeper chlorophyll-rich layers associated with phytoplankton in coastal waters (Fernández, 1979; Bautista et al., 1994). Early copepod nauplii feed on their oil sacs and then often on phytoplankton (Sekiguchi, 1974; Green et al., 1992). Because the swimming velocity of copepod nauplii is low, $0.5-2 \mathrm{~mm} \mathrm{~s}^{-1}$ (Mauchline, 1998), their ability to move horizontally is unlikely, however as they exhaust their oil sac, their buoyancy may change and they may further sink, leading to some ontogenetic control of their depth, which could lead to retention of later stage nauplii in deeper offshore waters (Mauchline, 1998; Golçalves et al., 2012).

The increase of copepod nauplii abundance during the cold phases of the internal tide in our study may have been due to advection when water from deeper offshore layers, abundant in nauplii, shoaled into the sampling site, and potentially further into the bay, related with the baroclinic southeastward current at depth, rather than due to accumulation, as they are not strong swimmers. The increase in 
chlorophyll and phytoplankton associated with deeper water when it shoals during the cold phase of the internal tide (Witman et al., 1993; Leichter et al., 1996; Ladah et al., 2012) could favour herbivorous copepod nauplii, advecting them close to their potential food source (Golçalves et al., 2012). As internal tidal waves propagate into the Bay of Todos Santos, they become increasingly non-linear as they cross shallower isobaths, eventually breaking entirely and forming bores before reaching shore (Filonov et al., 2014). Therefore, if organisms were advected during the cold phase of the internal tide, they could have been mixed into the water column, thereby avoiding being swept back offshore by the alternating flow. On the other hand, the pattern of increased abundance herein was similar to that found for crabs in a previous study in this region (Liévana-MacTavish et al., 2016). Crab larvae are strong swimming meroplankters and have the behaviour for accumulation (Shanks, 1983; Liévana-MacTavish et al., 2016). The increase in abundance measured herein for copepod nauplii in the cold phase could have been due to accumulation by the internal tidal front, by cumulative packets of high frequency internal waves, or by advection of water masses from depths where nauplii were more abundant.

Because early stages of ichthyoplankton such as fish eggs and vitelline larvae have positive buoyancy, we expected to find a strong stratified distribution in the water column, with higher abundances above the thermocline, and therefore predicted an increase in abundance in the surface stratum in the warm phase of the internal tide, similar to barnacle larvae (Helfrich and Pineda, 2003). However, our results showed no significant stratification (a requirement for some types of accumulation, see Helfrich and Pineda, 2003), low overall numbers, no significant temporal or depth changes in any internal tidal phase, and no relationship with currents. Some studies have found an accumulation of fish larvae in surface waters associated with high-frequency internal waves (Shanks, 1983; Kingsford and Choat, 1986). Very high frequency internal waves, seen in our physical data at the scale of minutes, were beyond the scope of this study due to the inability to sample the biology at that temporal scale, although if high-frequency internal waves were accumulating ichthyoplankton in the surface at this site, we might have expected some cumulative evidence of that (Lamb, 2002), as the warm phases we studied were replete with high frequency events. Overall, ichthyoplankton showed low abundances and high variability, most likely complicating the ability to detect a difference between depths and internal tidal phases, even if one did exist.

The ichthyoplankton samples we found were principally fish eggs, or fish larvae still in their yolk sac. This may indicate a spawning area nearby (Pittman and McAlpine, 2001). The fish larvae detected were species typical of this coastal area, e.g., Paralichthyidae spp., Scomber japonicus or Engraulix mordax (Moser, 1996; Valencia-Gasti et al., 2015). 
The high frequency of biological sampling required to study changes during the internal tide renders difficult this type of study. The data herein represent a significant observational effort at sea to produce relatively sparse coverage with high variability during limited periods. Plankton are generally patchy and the timing of the warm and cold phases of the internal tide cannot be predicted without some preliminary sampling, as these are highly non-linear events. Therefore, testing these predictions requires many hours of sampling to capture and resolve differences in abundances across both the cold and warm phases. For this reason, it is recommended that future studies sample for more days, over many tidal cycles, as frequently as possible, to guarantee that there will be enough samples and replicates during the period of strong internal tidal forcing, which in this site usually lasts only a few days. However, the issue of low numbers and patchiness in the plankton is often still unavoidable and not easily overcome, even with increased samples or replicates.

We predicted that the increase in abundance during the cold phase at depth found for nauplii could occur due to various forms of accumulation as explained in Helfrich and Pineda (2003). However, as discussed previously, advection of deeper water masses where copepod nauplii were more abundant, although less efficient, is another explanation of the patterns found. There could also have been a diel response that we were unable to detect, as we only sampled during the day. However, the likelihood that a diel migration would result in a confounded increase during the study period is low. The internal tide behaves differently each day, even on consecutive days, as it is a non-linear phenomenon and depends on stratification and barotropic tidal forcing, which also change from day to day and hour to hour. Finally, the idea that the patterns observed were due to sampling the same circulating patch of plankton on the consecutive days and that this resulted in the patterns observed is unlikely per the particle vector analysis on water parcel movement (see supplementary material), although we cannot completely rule this out as there is no way of knowing the extent of the patch being sampled. Regardless of the mechanism, we were able to support our predictions that even weak swimming, holoplanktonic organisms, with strongly stratified distributions above and below the thermocline, can show significant changes in abundance during the internal tide at the depth where they have their highest abundance, similar to many meroplanktonic organisms studied to date.

\section{CONCLUSIONS}

Using the two phase internal wave model and what has been previously established for meroplankton studies, we were able to predict an increase of copepod nauplii, but not groups of ichthyoplankton, during the internal tide. We conclude that they differed in their responses to internal tidal forcing 
because of differences in their buoyancy and depth distribution (copepods sink and are abundant at depth, whereas fish eggs and larvae did not show any significant stratification in their depth distribution). Understanding how the internal tide impacts zooplankton groups beyond just intertidal meroplankton such as barnacles is important for modelling coastal productivity, particularly at small scales, and for ultimately understanding transport. A deeper understanding of the behaviour of different zooplankton organisms (ichthyoplankton and holoplankton) in coastal areas is required to increase our knowledge of productivity in the nearshore during dynamic internal tide events. This is important for teasing apart how the internal tide, mesoscale, and seasonal processes are all nested together.

\section{ACKNOWLEDGEMENTS}

We thank the entire Interdisciplinary Coastal Ecology (ICE) team at CICESE and all the volunteers on the FLOO (Fluxes Linking the Offshore and the Onshore) projects.

\section{FUNDING}

This work was supported by CONACyT project (221662) awarded to LBL. LSV acknowledges the CONACyT Fronteras de la Ciencia (contract 2015-2-280) project for support.

\section{REFERENCES}

Baines, P.G. (1982) On internal tide generation models. Deep Sea Res. Part A, Oceanogr. Res. Pap., 29, $307-338$.

Bautista, B., Harris, R.P., Rodriguez, V. and Guerrero, E. (1994) Temporal variability in copepod fecundity during two different spring bloom periods in coastal waters off Plymouth (SW England). $J$. Plankton Res., 16, 1367-1377.

Fernández, F. (1979) Nutrition Studies in the Nauplius Larva of Calanus pacificus (Copepoda: Calanoida). Mar. Biol., 53, 131 - 147.

Filonov, A., Lavín, M. F., Ladah, L. B. and Tereshchenko, I. (2014) Spatial variability of internal waves in an open bay with a narrow steep shelf in the Pacific off NW Mexico. Cont. Shelf Res., 78, $1-15$. 
Franks, P. J. S. (1992) Sink or swim: accumulation of biomass at fronts. Mar. Ecol.: Prog. Ser., 82, $1-12$.

Franks, P. J. S. (1997) New models for the exploration of biological processes at fronts. J. Mar. Sci., 54, 161-167.

Godin, G. (1991) The analysis of tides and currents. Tidal Hydrodynamics. 675-709.

Golçalves, A.M.M., Pardal, M.A., Marques, S.C., Mendes, S., Fernández-Gómez, M.J., GalindoVillardón, M.P. and Azeiteiro, U.M. (2012) Diel vertical behaviour of Copepoda community (naupliar, copepodites and adults) at the boundary of a temperature estuary and coastal waters. Estuarine, Coastal and Shelf Sci., 98, 16 - 30.

Green, E.P., Harris, R.P. and Duncan, A. (1992) The production and ingestion of faecal pellets by nauplii of marine calanoid copepods. J. Plankton Res., 14, 1631-1643.

Haury, L. R., McGowan, J. A. and Wiebe, P. H. (1978) Patterns and processes in the time-space scales of plankton distributions. In: Spatial Pattern in plankton communities. NATO Conf. Ser., 3, 277-327.

Haury, L. R., Wiebe, P. H., Orr, M. H., and Briscoe, M. G. (1983) Tidally generated high-frequency internal wave packets and their on plankton in Massachusetts Bay. J. Mar. Res., 41, 65 - 112.

Helfrich, K. R. and Pineda, J. (2003) Accumulation of particles in propagating fronts. Limnol. Oceanogr., 48, 1509 - 1520.

Helfrich, K. R. and Melville, W. K. (2006) Long nonlinear internal waves. Annu. Rev. Fluid Mech., 38, $395-425$.

Ibáñez-Tejero, L., Ladah, L. B., Sánchez-Velasco, L., Barton, E. D. and Filonov, A. (2018) Vertical distribution of zooplankton biomass during internal tidal forcing under mesoscale conditions of upwelling and relaxation. Cont. Shelf Res., 171, 1 - 11.

Kingsford, M. J. and Choat, J. H. (1986) Influence of surface slicks on the distribution and onshore movements of small fish. Mar. Biol., 91, $161-171$.

Kundu, P.K., Allen, J.S, 1976. Some Three-Dimensional Characteristics of Low-Frequency Current Fluctuations near the Oregon Coast. J. Phys. Oceanogr., 6, 181-199.

Ladah, L. B., Tapia, F. J., Pineda, J. and López, M. (2005) Spatially heterogeneous, synchronous settlement of Chthamalus spp. larvae in northern Baja California. Mar. Ecol.: Prog. Ser., 302, 177185. 
Ladah, L. B., Filonov, A., Lavín, M. F., Leichter, J. J., Zertuche-González, J. A. and Pérez-Mayorga, D. M. (2012) Cross-shelf transport of sub-thermocline nitrate by the internal tide and rapid (3-6h) incorporation by an inshore macroalga. Cont. Shelf Res., 42, 10-19.

Lamb, K. G. (1997) Particle transport by nonbreaking, solitary internal waves. J. Geophys. Res., 102, $18641-18660$.

Lamb, K. G. (2002) A numerical investigation of solitary internal waves with trapped cores formed via shoaling. J. Fluid Mech., 451, 109-44.

Lamb, K. G. (2013) Internal tide breaking and dissipation mechanisms on the continental shelf slope/shelf. Annu. Rev. Fluid Mech., 46, 231 - 254.

Lee, R. F., Hagen, W., Kattner, G. (2006) Lipid storage in marine zooplankton. Mar. Ecol.: Prog. Ser., 307, 273-306.

Leichter, J. J., Wing, S. R., Miller, S. L. and Denny, M. W. (1996) Pulsed delivery of subthermocline water to Conch Reef (Florida Keys) by internal tidal bores. Limnol. Oceanogr., 41, 1490 - 1501.

Leichter, J. J., Shellenbarger, G., Genovese, S. J. and Wing, S. R. (1998) Breaking internal waves on a Florida (USA) coral reef: a plankton pump at work? Mar. Ecol.: Prog. Ser., 166, 83-97.

Liévana-MacTavish, A., Ladah, L. B., Lavín, M.F., Filonov, A., Tapia, F. J. and Leichter, J. (2016) High frequency (hourly) variation in vertical distribution and abundance of meroplanktonic larvae in nearshore waters during strong internal tidal forcing. Cont. Shelf Res., 117, 92- 99.

Liévana-MacTavish, A. and Ladah, L. B. (2017) Supply-side control over the survivorship of Chthamalus spp. recruits in northern Baja California. Mar. Biol. Res., 13, 733 - 743.

Mauchline, J. (1998) The biology of Calanoid copepods. Adv. Mar. Biol., 33, 1-710.

McCulloch, A. and Shanks, A. L. (2003) Topographically generated fronts, very nearshore oceanography and the distribution and settlement of mussel larvae and barnacle cyprids. J. Plankton Res., 25, $1427-1439$.

Morgan, S. G., Fisher, J. L., Miller, S. H., McAfee, S. T. and Largier, J. L. (2009) Nearshore larval retention in a region of strong upwelling and recruitment limitation. Ecology, 90, 3489 - 3502.

Morgan, S. G. and Fisher, J. L. (2010) Larval behaviour regulates nearshore retention and offshore migration in an upwelling shadow and along the open coast. Mar. Ecol.: Prog. Ser., 404, 109 - 126. 
Moser, G. H. (ed.) (1996) The early stages of fishes in the California Current region. In CaLCOFI Atlas No.33, NOAA-NMFS-SFSC, Allen Press, Inc., Lawrence, Kansas.

Pineda, J. (1991) Predictable upwelling and the shoreward transport of planktonic larvae by internal tidal bores. Science, 253, 548-551.

Pineda, J. (1994) Internal tidal bores in the nearshore: Warm-water fronts, seaward gravity currents and the onshore transport of neustonic larvae. J. Mar. Res., 52, 427-458.

Pineda, J. (1999) Circulation and larval distribution in internal tidal bore warm fronts. Limnol. Oceanogr., 44, 1400-1414.

Pineda, J. (2000) Linking larval settlement to larval transport: assumptions, potentials, and pitfalls. Oceanogr. Eastern Pacific, 1, 84-105.

Pineda, J., Hare, J. A. and Sponaugle, S. (2007) Larval transport and dispersal in the coastal ocean and consequences for population connectivity. Oceanography, 20, 22-39.

Pineda, J., Reyns, N. B., Starczak, V. R. (2009) Complexity and simplification in understanding recruitment in benthic popultations. Popul. Ecol., 51: 17 - 32 .

Pineda, J. and Reyns, N. (ed.) (2018) Larval transport in the coastal zone: biological and physical processes. In. Evolutionary Ecology of Marine Invertebrate Larvae. Edited byTyler J. Carrier, Adam M. Reitzel, and Andreas Heyland: Oxford University Press.

Pittman, S. J. and McAlpine, C. A. (2001) Movements of marine fish and decapod crustaceans: Process, Theory and Application. Adv. Mar. Biol., 44, 205 - 294.

Sandstrom, H. and Elliott, J. A. (1984) Internal tide and solitons on the Scotian shelf: a nutrient pump at work. J. Geophys. Res.: Oceans, 89, 6415-6426.

Sekiguchi, H. (1974) Relation between the ontogenetic vertical migration and mandibular gnathobase in pelagic copepods. Bulletin of the Faculty of Fisheries, Mie University, 1, 1-10.

Scotti, A. and Pineda, J. (2007) Plankton accumulation and transport in propagating nonlinear internal fronts. J. Mar. Res., 65, 117-145.

Shanks, A., (1983) Surface slicks associated with tidally forced internal waves may transport pelagic larvae of benthic invertebrates and fishes shoreward. Mar. Ecol.: Prog. Ser., 13, 311-315. 
Shanks, A. L. and McCulloch, A. (2003) Topographically generated fronts, very nearshore oceanography, and the distribution of chlorophyll, detritus, and selected diatom and dinoflagellate taxa. Mar. Biol., 143, 969-980.

Stibor, H., Vadstein, O., Diehl, S., Gelzleichter, A., Hansen, T., Hantzsche, F., Katechakis, A., Lippert, B. et al. (2004) Copepods act as a switch between alternative trophic cascades in marine pelagic food webs. Ecol. Let., 7, $321-328$.

Tapia, J. T. and Pineda, J. (2007) Stage - specific distribution of barnacle larvae in nearshore waters: potential for limited dispersal and high mortality rates. Mar. Ecol.: Prog. Ser., 342, 177 - 190.

Tapia, J. F., DiBacco, C., Jarrett, J. and Pineda, J. (2010) Vertical distribution of barnacle larvae at a fixed nearshore station in southern California: Stages-specific and diel patterns. Estuarine, Coastal and Shelf Sci., 86, $265-270$.

Valencia-Gasti, J. A., Baumgartner, T. and Durazo, R. (2015) Effects of ocean climate on life cycles and distribution of small pelagic fishes in the California Current System off Baja California. Cienc. Mar., 41, 315 - 348 .

Vlasenko, V., Stashchuk, N., Hutter, K. (ed.) (2005) Baroclinic Tides: Theoretical Modeling and Observational Evidence. Cambridge University Press, Cambridge, UK.

Witman, J. D., Leichter, J. J., Genovese, S. J. and Brooks, D. A. (1993) Pulsed phytoplankton supply to the rocky subtidal zone: Influence of internal waves. Proc. Natl. Acad. Sci. U.S.A., 90, $1686-$ 1690.

Zar, J. H. (ed.) (2010) Biostatistical analysis. 5th edition. Pearson Prentice Hall, Upper Saddle River, New Jersey. 


\section{TABLE AND FIGURE LEGENDS}

Table I. Factorial ANOVA, with internal tidal phase (cold vs. warm) vs. strata (surface and bottom) for fish eggs, fish larvae and copepod nauplii.

Table II. Principal fish larvae identified and their life stage. The majority had the yolk sac (79.52\%), with a small percentage in the pre-flexion (18.57\%) and flexion $(1.91 \%)$ stages. Fish larvae made up $31.66 \%$ of the ichthyoplankton quantified, with $68.34 \%$ being fish eggs.

Table III. Correlation results for the relationships between zooplankton abundance (fish eggs, fish larvae and copepod nauplii) and the movement of the water (the integral of the current [u', v', U', V'], as in Liévana-MacTavish et al., 2016), temperature, sea level and kinetic energy, for each stratum over a period of $30 \mathrm{~min}$ before and $30 \mathrm{~min}$ after (60 $\mathrm{min}$ in total) each biological sample collection time. Significant correlations are shown in red $(\mathrm{p}<0.05)$.

Fig. 1. (a) Location, (b) Study area: N4 (30 m depth) indicates the sampling site for net hauls, and the thermistor line and ADCP deployment; arrows show alongshore v' and onshore u' flow direction.

Fig.2. For the period 19 - 20 August, 2009 at N4: (a) Sea level. (b) Temperature vs. depth; heavy black line shows $15{ }^{\circ} \mathrm{C}$ isotherm (thermocline); overlaid white circles represent the abundance of fish eggs with abundances ranging from 0.44 to 9.14 ind. $\mathrm{m}^{-3}$ (dots are zero abundance). (c) Onshore (positive towards $34^{\circ}$ ) current component U' vs. depth; overlaid white circles represent the abundance of fish larvae, with abundances ranging from 0.12 to 10.54 ind. $m^{-3}$ (dots are zero abundance). (d) Alongshore (negative towards $56^{\circ}$ ) current component V' vs. depth; overlaid white circles represent copepod nauplii, with abundances ranging from 2.11 to 2402.2 ind. $m^{-3}$. In (b), (c) and (d), the black crosses correspond to times with no biological data. The vertical dotted blue line corresponds to the start of the cold phase and the vertical red line corresponds to the start of the warm phase. In (d), the blue rectangle represents sunrise and black rectangle represents sunset.

Fig. 3. Mean abundances of organisms in each internal tidal phase (cold and warm) and stratum (surface and bottom) for (a) fish eggs; (b) fish larvae; (c) copepod nauplii. Vertical bars denote standard error. Numbers above each line show P values comparing the two internal tidal phases for each strata when less than 0.05 from the post-hoc Fisher LSD. NS denotes not significant.

Fig. 4. Abundance vs. alongshore total current v': (a) Fish eggs; (c) Fish larvae; (e) Copepod nauplii. Abundance vs. alongshore internal tide (baroclinic) current V': (b) Fish eggs; (d) Fish larvae; (f) copepod nauplii. Red circles represent abundance in surface stratum; green circles represent abundance in mid-water stratum; blue circles represent abundance in bottom stratum. 


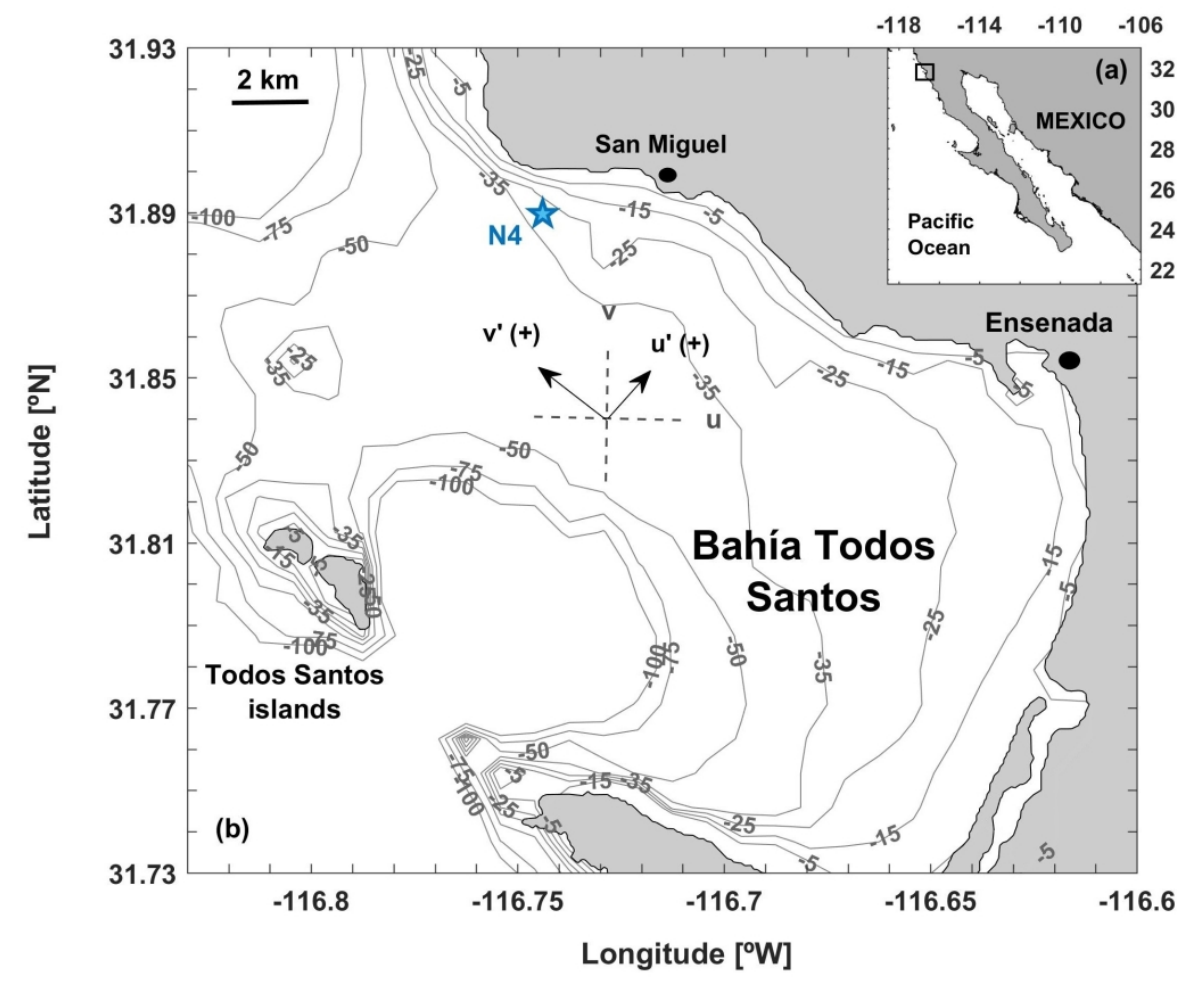

Fig. 1. (a) Location, (b) Study area: N4 (30 m depth) indicates the sampling site for net hauls, and the thermistor line and ADCP deployment; arrows show alongshore $v^{\prime}$ and onshore $u^{\prime}$ flow direction.

\section{$632 \times 500 \mathrm{~mm}(96 \times 96 \mathrm{DPI})$}




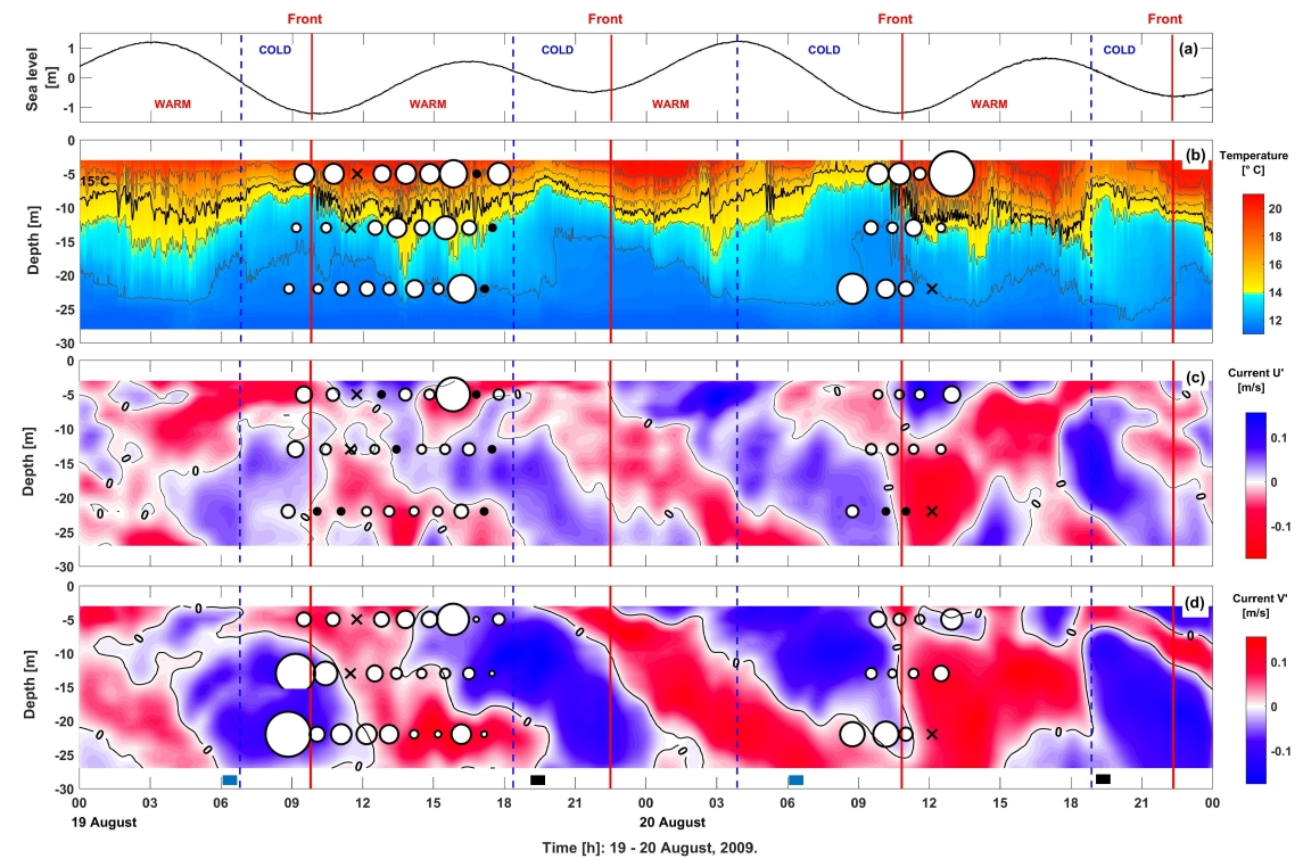

Fig.2. For the period 19 - 20 August, 2009 at N4: (a) Sea level. (b) Temperature vs. depth; heavy black line shows $15^{\circ} \mathrm{C}$ isotherm (thermocline); overlaid white circles represent the abundance of fish eggs with abundances ranging from 0.44 to 9.14 ind. $\mathrm{m}^{\wedge}(-3)$ (dots are zero abundance). (c) Onshore (positive towards $34^{\circ}$ ) current component $\mathrm{U}^{\prime}$ vs. depth; overlaid white circles represent the abundance of fish larvae, with abundances ranging from 0.12 to 10.54 ind. $\mathrm{m}^{\wedge}(-3)$ (dots are zero abundance). (d) Alongshore (negative towards $56^{\circ}$ ) current component $V^{\prime}$ vs. depth; overlaid white circles represent copepod nauplii, with abundances ranging from 2.11 to 2402.2 ind. $m^{\wedge}(-3)$. In (b), (c) and (d), the black crosses correspond to times with no biological data. The vertical dotted blue line corresponds to the start of the cold phase and the vertical red line corresponds to the start of the warm phase. In (d), the blue rectangle represents sunrise and black rectangle represents sunset.

$1270 \times 877 \mathrm{~mm}(96 \times 96 \mathrm{DPI})$ 

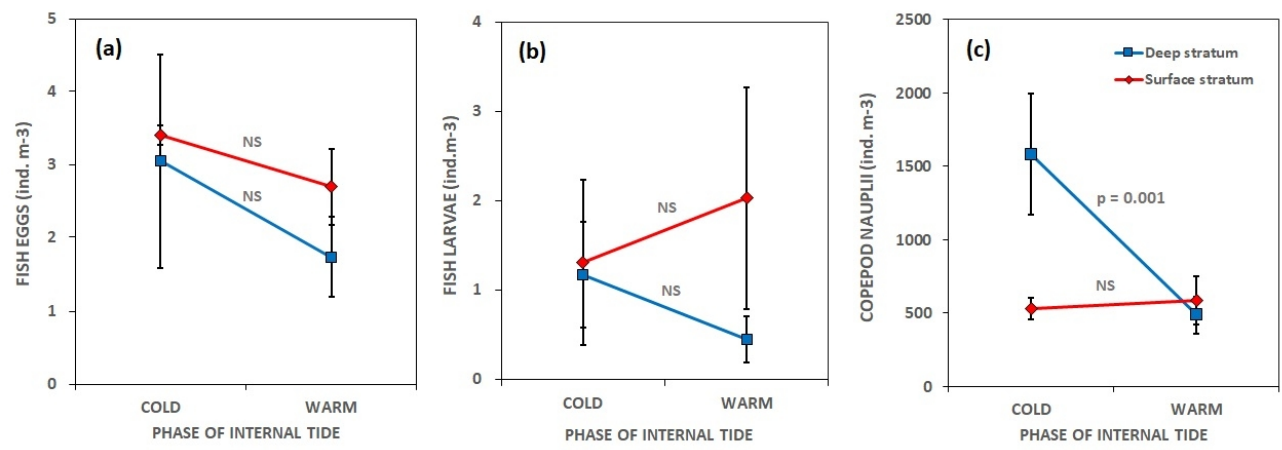

Fig. 3. Mean abundances of organisms in each internal tidal phase (cold and warm) and stratum (surface and bottom) for (a) fish eggs; (b) fish larvae; (c) copepod nauplii. Vertical bars denote standard error. Numbers above each line show $\mathrm{P}$ values comparing the two internal tidal phases for each strata when less than 0.05 from the post-hoc Fisher LSD. NS denotes not significant.

$223 \times 80 \mathrm{~mm}(144 \times 144$ DPI $)$ 

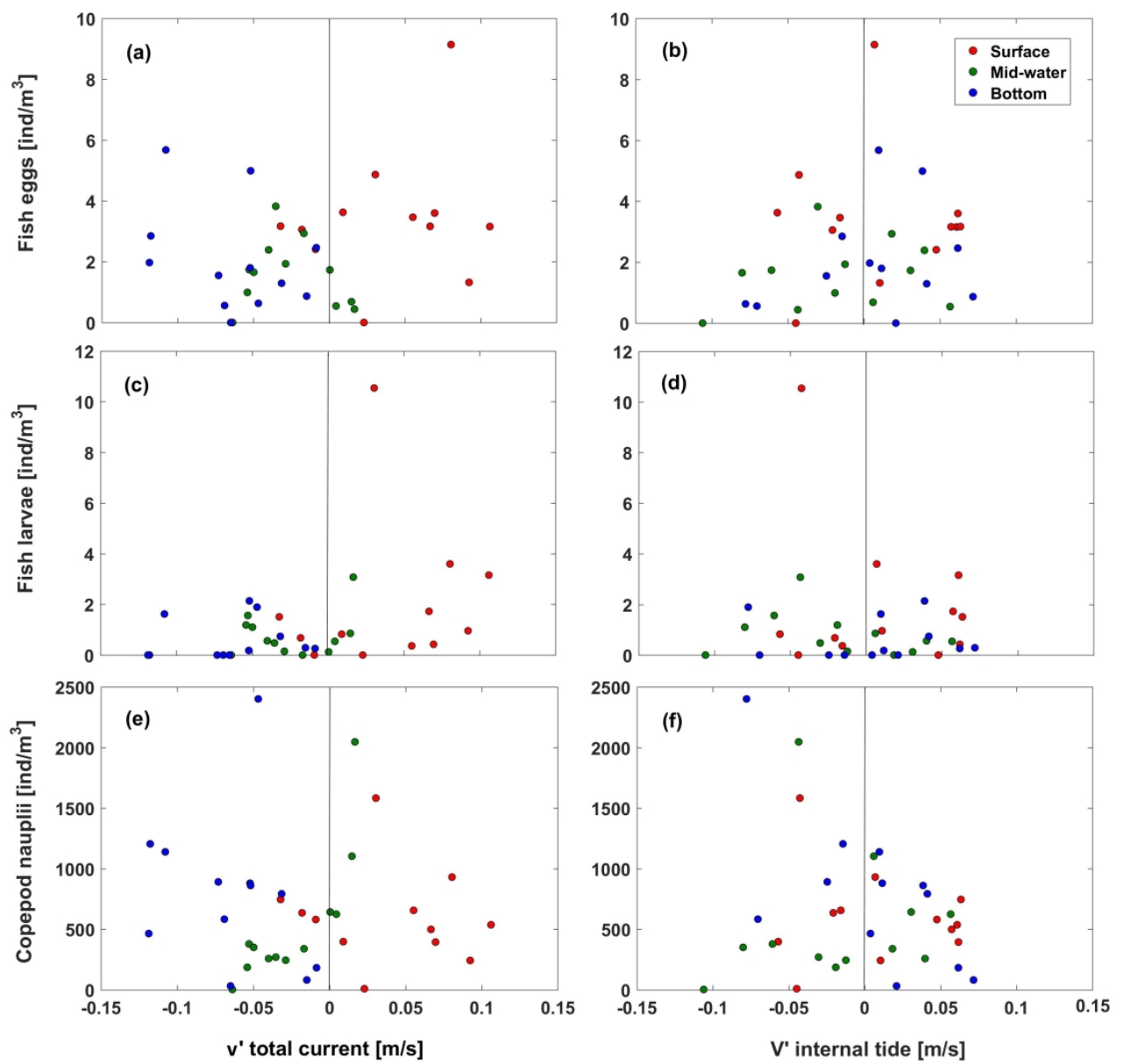

Fig. 4. Abundance vs. alongshore total current v': (a) Fish eggs; (c) Fish larvae; (e) Copepod nauplii. Abundance vs. alongshore internal tide (baroclinic) current $V^{\prime}$ : (b) Fish eggs; (d) Fish larvae; (f) copepod nauplii. Red circles represent abundance in surface stratum; green circles represent abundance in mid-water stratum; blue circles represent abundance in bottom stratum.

$656 \times 635 \mathrm{~mm}(144 \times 144$ DPI $)$ 


\section{TABLES}

Table I.

\begin{tabular}{|c|c|c|c|c|c|}
\hline FISH EGGS & SS & DF & MS & $\mathbf{F}$ & $\mathbf{p}$ \\
\hline Phase & 4.434 & 1 & 4.434 & 1.781 & 0.199 \\
\hline Strata & 1.881 & 1 & 1.881 & 0.755 & 0.396 \\
\hline Phase*Strata & 0.398 & 1 & 0.398 & 0.16 & 0.694 \\
\hline Error & 44.825 & 18 & 2.49 & & \\
\hline $\begin{array}{c}\text { FISH } \\
\text { LARVAE }\end{array}$ & SS & DF & MS & F & $\mathbf{p}$ \\
\hline Phase & $<0.001$ & 1 & $<0.001$ & $<0.001$ & 0.998 \\
\hline Strata & 3.238 & 1 & 3.238 & 0.605 & 0.447 \\
\hline Phase*Strata & 2.251 & 1 & 2.251 & 0.42 & 0.525 \\
\hline Error & 96.389 & 18 & 5.355 & & \\
\hline $\begin{array}{c}\text { COPEPOD } \\
\text { NAUPLII }\end{array}$ & SS & DF & MS & $\mathbf{F}$ & $\mathbf{p}$ \\
\hline Phase & 1180062 & 1 & 1180062 & 6.2 & 0.023 \\
\hline Strata & 987033 & 1 & 987033 & 5.185 & 0.035 \\
\hline Phase*Strata & 1455495 & 1 & 1455495 & 7.647 & 0.013 \\
\hline Error & 3426228 & 18 & 190346 & & \\
\hline
\end{tabular}


Table II.

\begin{tabular}{|c|c|c|c|}
\hline FAMILY & SPECIES & \multicolumn{2}{|c|}{$\begin{array}{l}\text { TOTAL LARVAE } \\
\text { (ind) }\end{array}$} \\
\hline \multirow[t]{5}{*}{ Paralichthyidae } & Citharichthys stigmaeus & Yolk sac & 64 \\
\hline & & Pre-flexion & 8 \\
\hline & Paralichthys californicus & Yolk sac & 3 \\
\hline & & Pre-flexion & 1 \\
\hline & Hippoglossina stomata & Yolk sac & 2 \\
\hline \multirow[t]{2}{*}{ Labridae } & & Yolk sac & 31 \\
\hline & & Pre-flexion & 4 \\
\hline \multirow[t]{2}{*}{ Engraulidae } & Engraulis mordax & Yolk sac & 19 \\
\hline & & Pre-flexion & 11 \\
\hline Scombridae & Scomber japonicus & Yolk sac & 25 \\
\hline \multirow[t]{5}{*}{ Serranidae } & Paralabrax clathratus & Yolk sac & 8 \\
\hline & & Pre-flexion & 3 \\
\hline & & Flexion & 1 \\
\hline & Others & Yolk sac & 6 \\
\hline & & Pre-flexion & 4 \\
\hline \multirow[t]{2}{*}{ Clupeidae } & Sardinops sagax & Yolk sac & 5 \\
\hline & & Pre-flexion & 2 \\
\hline \multirow[t]{3}{*}{ Others } & & Yolk sac & 2 \\
\hline & & Pre-flexion & 6 \\
\hline & & Flexion & 3 \\
\hline \multirow[t]{2}{*}{ Unidentified } & & Yolk sac & 2 \\
\hline & & Destoyed & 6 \\
\hline
\end{tabular}


Table III.

\begin{tabular}{|c|c|c|c|c|c|c|c|c|c|c|c|c|c|c|c|}
\hline & & \multicolumn{2}{|c|}{$\begin{array}{l}\text { u' (Total } \\
\text { current) }\end{array}$} & \multicolumn{2}{|c|}{$\begin{array}{l}\text { U' (Baroclinic } \\
\text { current) }\end{array}$} & \multicolumn{2}{|c|}{$\begin{array}{l}\text { v' (Total } \\
\text { current) }\end{array}$} & \multicolumn{2}{|c|}{$\begin{array}{l}\text { V' (Baroclinic } \\
\text { current) }\end{array}$} & \multicolumn{2}{|c|}{ Temperature } & \multicolumn{2}{|c|}{ Sea level } & \multicolumn{2}{|c|}{ Kinetic energy } \\
\hline & & $r$ & $p$ & $r$ & $p$ & $r$ & $p$ & $r$ & $p$ & $r$ & $p$ & $r$ & $p$ & $r$ & $\mathrm{p}$ \\
\hline \multirow{3}{*}{$\begin{array}{l}\text { FISH } \\
\text { EGGS }\end{array}$} & Surface & 0.207 & 0.52 & 0.195 & 0.544 & 0.074 & 0.82 & 0.022 & 0.95 & 0.102 & 0.753 & -0.145 & 0.654 & -0.354 & 0.259 \\
\hline & Mid-water & -0.171 & 0.596 & -0.206 & 0.521 & 0.184 & 0.567 & 0.223 & 0.486 & 0.447 & 0.145 & 0.329 & 0.296 & -0.475 & 0.118 \\
\hline & Bottom & 0.314 & 0.32 & 0.39 & 0.21 & 0.294 & 0.354 & 0.222 & 0.488 & 0.344 & 0.274 & 0.012 & 0.971 & -0.189 & 0.556 \\
\hline \multirow{3}{*}{$\begin{array}{l}\text { FISH } \\
\text { LARVAE }\end{array}$} & Surface & -0.193 & 0.548 & 0.17 & 0.598 & -0.259 & 0.416 & -0.214 & 0.503 & 0.257 & 0.42 & 0.248 & 0.437 & 0.114 & 0.723 \\
\hline & Mid-water & -0.231 & 0.47 & -0.3 & 0.35 & -0.274 & 0.388 & -0.28 & 0.379 & -0.571 & 0.053 & -0.355 & 0.257 & 0.116 & 0.72 \\
\hline & Bottom & 0.55 & 0.064 & 0.546 & 0.066 & -0.077 & 0.813 & -0.05 & 0.878 & 0.214 & 0.503 & 0.138 & 0.669 & 0.204 & 0.525 \\
\hline \multirow{3}{*}{$\begin{array}{l}\text { COPEPOD } \\
\text { NAUPLII }\end{array}$} & Surface & 0.008 & 0.98 & 0.001 & 0.998 & -0.125 & 0.7 & -0.106 & 0.742 & 0.198 & 0.537 & 0.176 & 0.584 & -0.205 & 0.523 \\
\hline & Mid-water & 0.093 & 0.772 & -0.068 & 0.833 & 0.029 & 0.93 & 0.098 & 0.763 & -0.313 & 0.322 & -0.476 & 0.118 & -0.239 & 0.455 \\
\hline & Bottom & 0.401 & 0.196 & 0.418 & 0.176 & -0.673 & 0.017 & -0.668 & 0.018 & -0.537 & 0.072 & -0.569 & 0.054 & -0.274 & 0.389 \\
\hline
\end{tabular}




\section{SUPPLEMENTAL MATERIAL - PVD}

Methods:

Pseudo-trajectories were calculated using progressive vector diagrams (equation 1) for each depth layer for the surface, mid-water and bottom strata. This analysis gives an idea of the displacement of the water parcel and its contents (e.g. zooplankton) from the sampling point over time (Thompson and Emery, 2014).

$$
(\mathrm{x}, \mathrm{y})=\left(\mathrm{x}_{0}, \mathrm{y}_{0}\right)+\sum\left(u_{i} v_{i}\right) \Delta t_{i}
$$

where, $\mathrm{x}_{0}, \mathrm{y}_{0}$ is the origin of the parcel of water, $u_{i} v_{i}$ the components of current for the times $\Delta t_{i}$ for observation $\mathrm{i}=1,2,3, \ldots$

\section{$\underline{\text { Results: }}$}

\section{Movement of water parcels around the sampling point}

The pseudo-trajectories (Fig. 1a- f) showed flow was generally out of the bay to the northwest in the surface stratum. Warm layer oscillations associated to ebb and flood current flows at the semidiurnal frequency can be seen (Fig. 1a). In the mid-water stratum, where the greatest internal wave displacement of isotherms occurs, the flow was towards the inside of the bay (Fig. 1b). In the deep stratum, the flow was to the southwest, with a direct flow in the offshore direction during the first 24 hours, after which time the flow showed oscillatory ebb and flood current flows (Fig. 1c).

However, when the subtidal flow was removed, the oscillation of the internal tide could be more clearly observed (Fig. 1d, e, f). In the surface layer, the flow oscillated north of the sampling site (N4 at $0 \mathrm{~h}$ ) during the first 24 hours and the flow oscillated south of the sampling site between $30-48 \mathrm{~h}$. Although the flow would not have resulted in the return of specific water parcels to the sampling site during the second day, the internal tidal flow did oscillate near the site (Fig. 1d). The internal tidal flow tended to move to the southwest in the mid-water stratum (Fig. 1e). Finally, in the deep stratum, a clear oscillation of the flow occurs south of the sampling site during the first 24 hours and north of the sampling site during the second 24 hours on the second day. The internal tidal flow did not result in parcels returning to the sampling site in any stratum (Fig. 1f). 


\section{$\underline{\text { Discussion: }}$}

Pseudo-trajectories suggested the same patch was not sampled on the different days of the study, however this is difficult to deduce based solely on the current flows of the water parcels because we have no information on patch size or extent. Patch size depends on many different processes at various spatiotemporal scales (Marquet et al., 1993). The changes in the abundance of planktonic organisms shown in the present study might be associated with different planktonic concentrations above and below the thermocline, as has been modelled for internal waves (Lennert-Cody and Franks, 1999). The effect of the mesoscale upwelling event, the diurnal sea breeze, and the semidiurnal internal tide is evident in the trajectories for both days of study (Ibáñez-Tejero et al., 2018), all of which could have affected plankton patchiness in some way. Until a better way to sample plankton at smaller spatiotemporal scales is developed, net tows will be unable to determine patchiness as necessary and it remains an important yet untractable unknown.

\section{$\underline{\text { References: }}$}

Ibáñez-Tejero, L., Ladah, L. B., Sánchez-Velasco, L., Barton, E. D. and Filonov, A. (2018) Vertical distribution of zooplankton biomass during internal tidal forcing under mesoscale conditions of upwelling and relaxation. Cont. Shelf Res., 171, 1- 11.

Lennert-Cody, C.E. and Franks, P.J.S. (1999) Plankton patchiness in high-frequency internal waves. Mar. Ecol.: Prog. Ser., 186, 59-66.

Marquet, A.U., Pablo, A., Fortin, M.J., Pineda, J., Wallin, D.O., Clark, J., Yegang, W., Bollens, S., Jacobi, C.M., and Holt, R.D. (2013) Ecological and evolutionary consequences of patchiness: a marine-terrestrial perspective. In: Lecture Notes in Biomathematics, 96, 277 - 304.

Thomson, R.E. and Emery, W.J. (ed) (2014) Data Analysis Methods in Physical Oceanography, third ed. Elsevier, Oxford, UK. 


\section{Fig. 1:}

Pseudo-trajectories of the total currents from $0 \mathrm{~h} 19$ August to $0 \mathrm{~h} 21$ August 2009: (a) Surface stratum centered at $6 \mathrm{~m}$; (b) Mid-water stratum centered at $9 \mathrm{~m}$; (c) Bottom stratum centered at $18 \mathrm{~m}$. Pseudotrajectories of currents after removal of subtidal component: (d) Surface stratum centered at $6 \mathrm{~m}$; (e) Mid-water stratum centered at $9 \mathrm{~m}$; and (f) Bottom stratum centered at $18 \mathrm{~m}$. The numbers represent hours of day, $0 \mathrm{~h}$ to $48 \mathrm{~h}$ (with displacements marked every $3 \mathrm{hr}$ as in Fig. 2 of the manuscript) for 19 and 20 August, 2009. The black circle corresponds to the start of the trajectories at N4.
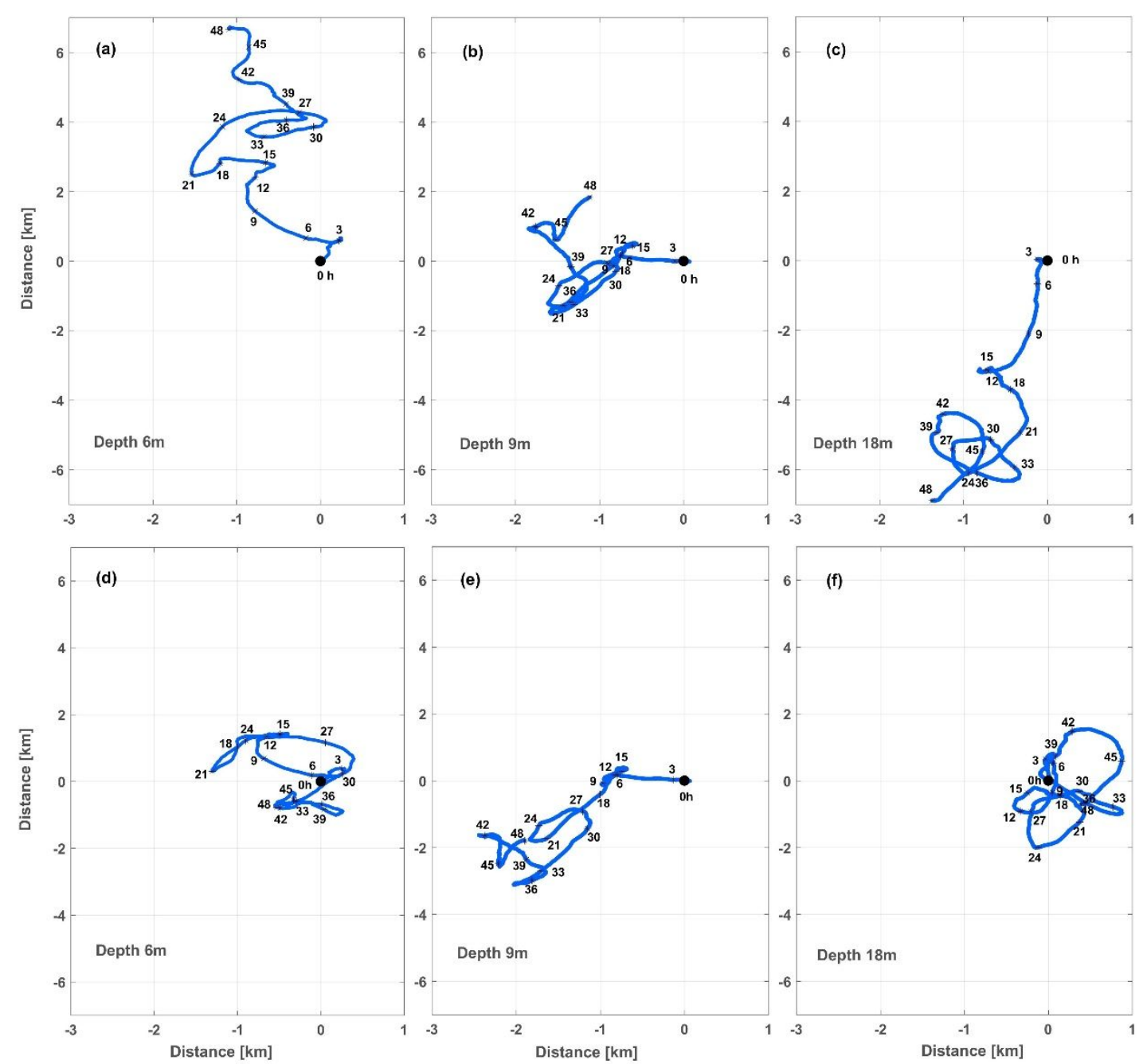